\title{
On the Strategies of Improving Oral Application Ability for Students of Non-English Majors
}

\author{
Xunfeng Yin \\ TaiShan University, Tai’an, Shandong, 271000, China
}

\begin{abstract}
The cultivation of students' oral application ability in college oral English teaching is a vital part of foreign language learners' communicative competence. Therefore, this paper introduces communication strategies into college English classroom teaching, and discusses the feasibility and effectiveness of communicative strategy training as well as the practical improvement of oral English competence, so as to achieve effective oral English classroom teaching in a real sense.
\end{abstract}

Index Terms - communication strategy, feasibility, effectiveness

\section{RESEARCH BACKGROUND}

There has been the rapid development of China's higher education, and it is the same case with college English teaching, which makes the conversion from the traditional classroom teaching to the diversified teaching mode, a comprehensive teaching mode based on computer network together with network-based autonomous learning to realize the effective teaching of intensive reading, listening and oral English. Meanwhile, the Ministry of Education pointed out that college English teaching should aim to improve students' comprehensive application ability, especially the listening and speaking ability. Therefore, oral English teaching gains an increasing attention of many experts and scholars home and abroad, and becomes the emphasis of teaching reforms in colleges and universities in China.

But oral English teaching for non-English majors based on multimedia network is still in the stage of exploration, and there exist many difficulties to conquer. To start with, the examination-oriented education in high school, especially in the third year, makes most of the students' basic knowledge of spoken English weak, which results in their silence in oral English class in universities. Besides, for the students of non-English major, the difficulties are even bigger: large classes with the number of students ranging from seventy to over ninety, insufficient class hours with only one class or two classes a week. Finally, the emphasis of oral English teaching for the non-English majors has been laid on improving students' language ability, neglecting the training of language application ability, which makes the students who have good language ability still fail to communicate with their counterparts smoothly.

Based on the above problems, we should not only aim at improving the students' language ability, but also improve the students' ability to apply the language so as to better the oral English teaching under the new teaching mode. Therefore, communication strategies, the language use strategy, can be introduced into the teaching of oral English for non-English majors.

\section{COMmunication STRATEGiES}

\section{A. Definitions of Communication Strategies}

The term "communicative strategy" was first raised by Selinker (1972) in his seminal paper on "interlanguage", referring to the skills adopted by second language learners to overcome communication barriers caused by limited language resources. Nevertheless, he did not dwell on the nature of communication strategies. Soon after that Savignon (1972) published a research report in which she highlighted the importance of coping strategies, which was the equivalent of communication strategies, in communicative language teaching and testing. Thereafter, different scholars, including Tarone (1980), Faerch \&Kasper (1983), Stern (1983), Ellis (1985), Brown (1987), Bialystok (1990) etc., put their definitions of communication strategy in terms of a psychological or communicative perspective.

Take Corder (1981, p.103) as an example, he raised that communication strategies are the systematic skills used by the speakers to express themselves when encountering difficulties. And Cohen (1998, p.68) defined linguistic strategies as teaching students how to use acquired language knowledge flexibly and effectively. Among the definitions, the widely accepted one was put forward by Faerch \&Kasper (1983, p.36), "communication strategies are potentially conscious plans for solving what to an individual presents itself as a problem in reaching a particular communicative goal".

\section{B. The Criteria for Communication Strategies}

From the above definitions, the distinctive features of communication strategies would be discerned, namely, problem-orientedness and consciousness. 
"problem-orientedness" originated from Bialystok's "problematicity", which referred to "the idea that strategies are used only when a speaker perceives that there is a problem which may interrupt communication" (Bialystok, 1990, p.3). And some other researchers developed the concept of "problem-orientedness" and defined the problems precisely, say, own-performance problems, other-performance problems, processing time pressure (Dörnyei\&Scott, 1997, p.182-183). Own-performance problems occur when one says something incorrect or partly correct and they are related to diversified types of self-repair, self-rephrasing and self-editing mechanisms; other-performance problems deemed as problematic exist in the interlocutor's speech due to the lack of complete understanding; processing time pressure refers to the frequent need of more time than would be naturally to process and plan the second language speech in the smooth communication, in which strategies like fillers, hesitation devices, and self- repetitions would be employed.

The second criterion is consciousness, as it is pointed out by Cohen (2000, p.4) that strategies are conscious techniques used to achieve a goal. There are three connotations in reference to consciousness according to Dörnyei and Scott (1997, p.183-185), that is, awareness of the problem; intentionality; awareness of strategic language use. Consciousness as the awareness of the problem means that speakers can only consciously recognize problem-based and language-processing communication strategies so as to distinguish mistakes and communication strategies that may have a similar erroneous form. As for the connotation of intentionality, it is the speaker's intentional use of communication strategies, which separates the strategies from other unintentional verbal behaviors. And finally awareness of strategic language use refers to the usage of imperfect devices for mutual understanding when making communication, in which code switch is a case in point to illustrate this point.

To sum up, problem-orientedness shows that it is of great importance to teach communication strategies as its objective is to tackle the problems in communication; meanwhile, consciousness indicates that the use of communication strategies is conscious, so it could be improved by intentional training of awareness.

Consequently, it is feasible to introduce communication strategies into the teaching of oral English for non-English majors. After all, not only language learners, but the native speakers, may turn to communication strategies to convey messages because of lack of language resources or temporary oblivion. So under such circumstances the use of communication strategies would furnish second language learners with many more opportunities to keep their communication smooth and successful.

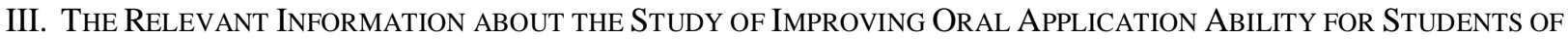 NON-ENGLISH MAJORS}

\section{A. Subjects of the Study}

In this study, sixty students from Taishan University in Shandong province, China, are chosen to be the subjects of research, among which thirty of them are from College of Liberal arts majoring in Chinese language and literature and the other thirty from College of Mathematics majoring in mathematics and applied mathematics. Such a choice of the subjects of the study aims to make a horizontal comparative study of liberal arts class and science class, hoping to identify the different characteristics of students of different majors so as to achieve an effective classroom teaching of oral English.

\section{B. Objectives of the Study}

In view of the present situation of oral English teaching in our university, the study is designed to get some ideas of the problems and difficulties of the students in their oral English learning. Moreover, the combination of oral English teaching and the learning of communication strategies could promote students to have a deeper understanding of western culture, and to provide a new perspective for the improvement of college oral English teaching. Specifically, the objectives of the study could be generalized as follows:

(1) Try to explore the feasibility of introducing communication strategies into college oral English classroom teaching to improve students' language application ability.

(2) Try to develop students' awareness that under different cultural background different communication strategies could be employed, which would be helpful for students to have a deeper understanding of Chinese culture and western culture.

\section{Methods of the Study}

During the study, selected students' oral English level was tested, their puzzles and difficulties in learning oral English were detected, their need of learning communication strategies was discussed and their final learning effect was evaluated comparatively. To achieve these targets, qualitative analysis method, literature summary method and comparative research method etc. were adopted to track the whole process of the study.

\section{THE PROCESS OF THE STUDY}

Based on the above introduction, selected students' language ability was analyzed in the first place before starting the teaching research. The analysis showed that all the selected students have at least six years or more of traditional English learning experience before entering Taishan University. Since they were from different regions and half of them 
belonged to a liberal arts class and the other half was from a science class, they did show some differences in vocabulary and grammar, but not very obvious. After the test taken at the time of their admission, it was estimated that their vocabulary size was three to four thousand, above average.

The experimenting began in the fall semester of 2013 and lasted two years, including about 120 days of winter vacation and summer vacation. The experimental feedback was conducted at the end of the second semester of sophomore year 2015, the spring semester of 2015. The students in each class were randomly divided into six groups, one leader in each group. The study was started in the following three stages:

\section{A. Pre-preparation Phase}

The first stage was the pre-preparatory phase, which lasted about four months. At the beginning of the study, from September 2013 to December 2013, the first semester of their first year of college, students' language ability, the difficulties and problems in their oral English learning were detected.

First of all, all the students were assembled to have a discussion about their oral English learning, which indicated that they all showed great interest in oral English learning, hoping to communicate smoothly and fluently in English in life, and that the problems and difficulties were disclosed to a large extent, including the feeling of helplessness, the lack of the systematic learning of phonetics, and the maladjustment of college oral English class etc.

Secondly, the oral pretest of recording was arranged for all the sixty students in the language lab. During the process of pretest, students were provided with three topics and with two minutes' preparation they made a presentation of at least two minutes in terms of the topic they chose. After analyzing the recording of the students, we found that although students from the liberal arts class were better than those in the science class in terms of vocabulary size, there were similar problems in the expression of language, for example, $80 \%$ of the students had difficulties in pronunciation, especially labiodentals sound, friction sound and nasal sound; while in terms of expression, $70 \%$ of the students failed to express their views fluently with the constant breaks in the process of speaking, and $20 \%$ of students could hardly say a complete sentence; the rest of the students were fluent and capable of stating their views in more complete sentences.

Thirdly, students were assigned assignments during the winter vacation of 2014, namely, during a period of about forty days they voluntarily practiced some basic knowledge of oral English with the relevant exercises sent to them by emails. At the beginning of the second stage, a test was carried out to make a survey.

\section{B. The Phase of Improving Language Competence}

The second phase was for the improvement of students' language proficiency, which lasted for about nine months, from January 2014 to September 2014, with one winter vacation and one summer vacation accounting for about 80 days. The first stage of group discussion and pre-tests showed that the selected students' language proficiency was relatively weak, which to a large extent affected their confidence in communicating in English. And the lack of basic knowledge of spoken language inevitably led to the ineffective English communication. Therefore, in this stage, students studied together once a week mainly through the way of collective instruction.

Before group learning, through classroom questioning and quizzes, it was found that $82 \%$ of students could not understand correctly the rules of phonological knowledge, and there were pronunciation errors in their previous voluntary oral training. Only $10 \%$ of the students had a good grasp of the pronunciation, and another $8 \%$ did not complete the assigned tasks. In view of the students' condition, the collective teaching of the basic knowledge of oral English focused on correcting pronunciation errors, analyzing rules such as liaison, strong and weak form, consonant clusters and intonation etc. During this process the team leaders were responsible for the large quantities of practice. Meanwhile, the counterpart oral English training of application ability was performed in the college oral English class teaching, with such forms as making a speech, group discussion, debate, role play and fun competitions etc.

At the end of the second stage, a follow-up test was carried out in the forms of group discussion and group oral performance test to get understanding of the improvement of students' English language ability. During the discussion, $90 \%$ of the students said that their language ability had been improved and the basic knowledge of oral English was grasped better. Only $10 \%$ of the students felt it was a struggle, but there was still progress. Moreover, in the process of the fifteen-minute oral tests, students were graded on the aspects of time, pronunciation and intonation, fluency of expression, integrity of the content and smoothness of the communication.

In addition, in order to strengthen the knowledge students learned in the second stage, they were arranged to practice further during the forty-day summer vacation in 2014.

\section{The Phase of Studying Communication Strategies}

The third phase aimed to enhance students' strategic capacity, lasted nine months from October 2014 to June 2015 , including a winter vacation of about 40 days. Different from the previous phases, students from the liberal art class were taught communication strategies once a week in extra-curricular time; in contrast, students from the science class were still trained in traditional oral English teaching as the controlled class. A questionnaire survey was conducted prior to the strategy training of the experimental class and it was learned that all students had no idea of communication strategies before, and they were willing to make the attempt to study the strategies, but they were not certain as for the necessity of teaching communication strategies.

The teaching mainly includes the history of the development of communication strategies in foreign countries, the 
definition and classification as well as the learning of major communicative strategies: avoidance strategy, paraphrase, approximation, word coinage, code switch, foreignizing, literal translation, appeals and non-linguistic strategies. The methods of strategy training used were as follows: making discussions about the strategies that students have used unconsciously when completing the learning task; introducing the new strategies by definitions and descriptions; illustrating the usage of the strategies with examples; providing a large amount of practice by the means of making definitions, describing pictures, playing the game of finding differences of similar pictures, giving instructions, and retelling stories, etc.

Through the study of communication strategies, students understood that it would be inevitable to encounter obstacles in communication, but with a considerable number of vocabularies, they could cope with these barriers by using communication strategies flexibly. Furthermore, students also comprehended which strategies could be more conducive to a successful communication and reflect the speakers' high communicative competence, for example, using achievement strategy more and avoidance strategy less; second language-based strategies more and first-language-based policies less. Of course, the above statements did not necessarily mean that students could not use such strategy as word coinage as it would be risky to produce some non-existent words and inappropriate statements, by contrast, such use of the strategy should be encouraged under the circumstance of insufficient vocabulary because it would contribute to a smooth communication.

At the end of this stage, all the sixty students were tested for impromptu oral communication, giving students three impromptu topics, and each group organized a performance of about ten minutes within a designated ten-minute period after the topic was selected. In order to ensure the appropriateness and the effectiveness of the test, another English teacher was included. The results showed that: firstly, after three stages of experimental teaching, all the sixty students have improved their language ability, decreased their pronunciation errors, and strengthened their ability of organizing language. Secondly, when the students from science class encounter barriers in communication, they intentionally turned to avoidance strategy, paraphrase, code switch, imitation and body language etc., to make the communication continue smoothly. At this point, they performed better than the students from liberal art class, 50\% of which unconsciously adopted the avoidance strategy and remained silence, which made the communication lack of fluency. Third, after the same training, students from the liberal art class are only slightly better than those in the science class in terms of language proficiency and language use ability, mainly reflected in the choice of words and the organization of sentences in communication.

\section{ANALysis AND CONCLUSIONS OF THE STUDY}

First of all, the first stage of research made it clear that although students of different majors are of different language level, they still shared such common problems as the insufficient phonological knowledge, the lack of oral English practice and the maladjustment of college oral English teaching etc. This indicated that language communication, in other words, language application ability was not only determined by the learners' language ability, therefore, the study on this subject was necessary to improve college students' English application ability.

Secondly, after the comparison and analysis of the large amount of the data accumulated in the second stage and the test results in the pre-preparation phase, it was suggested that $65 \%$ of the students had a great improvement in pronunciation, intonation, the fluency of the expression and the integrity of the content. For the remaining $35 \%$ of the students, there was no significant progress in the level of language proficiency, of which $28 \%$ were from the science class. After a separate interview with the $35 \%$ of the students, it was revealed that many factors led to the failure of their performance, such as, "so nervous at the time of the test that they forgot to correct the mistakes", "lack of the awareness of applying the learned knowledge to the real communication, and went back to the previous level at the start of the performance", or "having difficulties in understanding their group members' statements, so no effective response could be made". Hence, the study of this stage stated clearly that to improve language application ability and ensure smooth language communication, language competence was the basis. Besides, the failure of the small part of students in this stage showed that additional practice and follow-up track would be required for them, especially the students of science class because of their weaker language ability.

Thirdly, through the test results of the students in the third stage, it was shown that only paying attention to the cultivation of language ability in college oral English teaching could not guarantee the improvement of language application ability and the smooth progress of language communication; and that it was necessary to incorporate communication strategies into the college oral English classroom teaching, which could contribute to the improvement of college students' language application ability for both students of liberal arts class and those from science class.

\section{REFLECTIONS AND PROSPECTS FOR FOLLOW-UP STUDY}

This paper justified integrating oral communication strategies into college oral English teaching, and proved that students' language ability was improved and their application ability was developed, which would be beneficial to college oral English classroom teaching. However, in the process of implementation, there also occurred two problems. First, there was the problem of overcorrection in the class where communicative strategies were taught. $30 \%$ of students use avoidance strategy, code switch, imitation and body language significantly more than other strategies, which would 
also hinder normal language communication. Second, since the handouts on communication strategies sent to students were in the original English language, $60 \%$ of the students reflected that was difficult for them to read and increased the difficulty of understanding.

Consequently, it is a long-term process to improve college students' language application ability, so during the oral English teaching of students from Class of 2017 and 2019, I further checked and adjusted the design of the way to evaluate students' language ability, and made it more diversified in the detection of statistical tools, so as to really improve students' language application ability and finally promote college oral English teaching.

\section{REFERENCES}

[1] Bialystok E. (1990). Communication Strategies. Oxford: Blackwell.

[2] Brown, H. (1987). Principles of Language Learning and Teaching (2nd Ed.). Englewood Cliffs, NJ: Prentice Hall.

[3] Cohen, A.D. (1998). Strategies in Learning and Using a Second Language. Harlow, Essex: Longman.

[4] Cohen, A.D. (2000). Strategies in Learning and Using a Second Language. Beijing: Foreign Language Teaching and Research Press.

[5] Corder, P. (1981). Error Analysis and Interlanguage. Oxford: Oxford University Press.

[6] Dörnyei Z. \& Scott, M. L. (1997). Review Article Communication Strategies in a Second Language: Definitions and Taxonnomies. Language Learning. (47)1, 173-210.

[7] Ellis, R. (1985). Understanding Second Language Acquisition. Oxford: Oxford University Press.

[8] Faerch C \& Kasper G. (1983). Plans and strategies in foreign language communication. In C Faerch \& G Kasper (eds.). Strategies in Interlanguage Communication. Harlow, England: Longman, 20 - 60.

[9] Savignon, S. J. (1972). Communicative Competence: An experiment in Foreign-language Teaching. Philadelphia, PA: The Center for Curriculum Development.

[10] Selinker L. (1972). Interlanguage. International Review of Applied Linguistics, 10, 209 - 231.

[11] Stern, H. H. (1983). Fundamental Concepts of Language Learning. Oxford: Oxford University Press.

[12] Tarnoe, E. (1980). Communication strategies, Foreign Talk and Repair in Interlanguage. Language Learning. 4, 417-431.

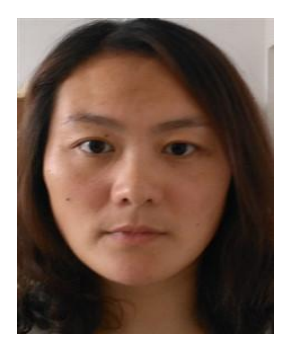

Xunfeng Yin was born in the city of Tai'an, Shandong Province, China in 1976. In March 2006, she earned the degree of M. A. in English in Tianjin Foreign Studies University, China, majoring in the theory and practice of translation.

Since graduated from QuFu Teachers' University in September 2000, she has been teaching English in Taishan University in Tai'an city, Shandong Province, China. In 2006, she was named Lecturer. And she published many articles about teaching and English translation, including On The Theory And Practice Of Translation of Eugene A. Nida. (2005). 唐山学院学报. 3, 34-36; On a Linguistic Theory of Translation of J.C.Catford. (2006). 大学英语教学研究. 10, 323-326; Gutt's Guts. (2007). International Journal of Educational Engineering. 6, 648-650, etc. She also is engaged in translation work besides the teaching of English intensive reading, listening and oral class.

Ms. Yin led two research projects on the school level and the provincial level, and participated in more than a dozen research projects. As the guide teacher, she also won the First Prize of Guide Teacher of the National College Students' English Contest in 2007, 2009 and 2010. 